\title{
HUMANISMO Y POÉTICA DEL ESPACIO: EL HABITAR COMO ESTÍMULO DE LOS PROCESOS INTERPRETATIVOS
}

Recibido: 1-10-2016

Aprobado: 18-11-2016

\author{
Adriana Masís Morales \\ Arquitecta independiente
}

\begin{abstract}
Adriana Masís Morales. Graduada en Arquitectura por la Universidad de Costa Rica, 2016. Se dedica al estudio de la arquitectura y la filosofía, sus correspondencias e influencia sobre la relación sujetoespacio. Como investigadora ha desarrollado la tesis titulada "Hermenéutica de la Arquitectura", que trata temas asociados a la percepción del espacio, su poética y vivencia, así como un acercamiento a la aplicación de la hermenéutica en el aprendizaje de los procesos proyectuales. Actualmente desarrolla proyectos e investigaciones de forma independiente. adrianama59@yahoo.es
\end{abstract}

\begin{abstract}
Resumen
"El humanismo [al igual que la hermenéutica] no es un sistema, es una refundación permanente, una lucha. Es una 'transvaloración' de valores, como decía Nietzsche. Esto supone conocer esos valores, apropiárselos y cuestionarlos" (Larroque, 2015, párr.5). Por esto, desde la perspectiva de los procesos interpretativos, humanizar el espacio implica comprender el proceso creativo no desde el problema determinado que encuentra su respuesta en la obra arquitectónica o la obra artística, sino desde la concepción de una cotidianidad que acumula y crea experiencias significativas que nos permiten reflexionar y activar nuevas versiones de lo prescrito.

Así las cosas, este enfoque transdisciplinario ha inspirado no solo invención teórica de una nueva perspectiva interpretativa destinada a sensibilizarnos sobre los procesos creativos, sino también, la activación de la poética como un recurso para 'estremecer' todos aquellos valores sociales y humanísticos presentes en el concepto de Habitar y en nuestro rol como habitantes del mundo.
\end{abstract}

Palabras Clave: habitar, poética, hermenéutica, proceso creativo, humanismo.

\begin{abstract}
"Humanism [as well as hermeneutics] is not a system, it is a permanent re-foundation, a fight. It is a transvaluation of values, in the words of Nietzsche. This means, knowing those values, appropriating them and questioning them" (Larroque, 2015, par.5). Hereby, from the perspective of interpretative processes, humanizing space involves understanding the creative process, not from a determined problem that finds it's answer in the work of architecture or in the work of art, but from the conception of an everydayness that accumulates and creates significant experiences, allowing us to meditate and activate new versions of what has been already established.

As things stand, this transdisciplinary approach has inspired not just the theoretical invention of a new interpretative perspective intended to sensitize ourselves about the creative processes, but also, the activation of poetics as a resource to 'shake' all those social and humanistic values, which are present in the Dwelling concept and in our role as world's inhabitants.
\end{abstract}

Key Words: dwelling; poetics, hermeneutics, creative process, humanism. 
Al reflexionar sobre lo que significa ser 'habitantes del mundo', se alude indiscutiblemente a la propia existencia del ser humano; y es ahí de donde parten los engranajes que comparten la Arquitectura y la Filosofía.

Asumir el reto que implica la comprensión de la Arquitectura como una unidad relacional $y$, por tanto, como una entidad que enlaza espacios y define competencias mucho antes que objetos, inaugura excitantes programas de trabajo que precisan de conocimientos compartidos. "(...) Así, la Arquitectura ha de ser, necesariamente, discutida y discutible, porque sólo bajo esta premisa se construye la polis" (Arenas L. \& Foqué U, 2011, párr. 2).

El ser humano y su relación con el mundo, junto con los espacios que configuran ese mundo, componen el eje central para una nueva teoría transdisciplinaria que analice el 'ser en el espacio', el habitar y la espacialidad en las prácticas sociales.

Sin embargo, el fuerte de esta investigación y su principal aporte se encuentran en la generación de una Hermenéutica de la Arquitectura, en donde se contempla la Poética del Espacio y la humanización de la experiencia espacial como señal de sensibilidad social.

En ese sentido, cuando Bachelard habla de Poética del Espacio quiere ir más allá de una descripción de los objetos en el espacio o de conceptualizar el espacio a través de ideas artificiosas (como han hecho otros filósofos); tocando así un punto clave, que es ver el espacio en términos de las emociones que despierta en el ser humano, la manera en la que los espacios transmiten, trascienden, y conmocionan de manera que acaban por apreciarse como poéticos.

(...) la epistemología bachelardiana se involucra directamente con el sentimiento humano; en consecuencia, no se conforma con describir los objetos que aparecen ante nosotros, como si estos nos fueran ajenos, sino que intenta encontrar el modo como tales objetos expresan un esquema imaginario oculto, fruto de una raíz imaginante, emotiva, que no obstante su diversidad formal, es constante a sí misma, a su propia imagen (Bachelard, 1997, p.9).

Este enfoque es representativo porque establece una forma de filosofar sobre lo fenomenológico sin abstraerse de lo real; del espacio vivenciado por el sujeto. Siendo este texto una manera de pensar innovadora para su época y un gran legado de un filósofo que 
además por sus orígenes en lo epistemológico dio grandes aportes en la construcción del conocimiento.

A través de sus ejemplos de la casa, Bachelard describe espacios con los que el propio lector puede identificarse, pero sin apelar a los objetos en sí, sino a los objetos como fenómeno; que nos afectan y nos proporcionan experiencias. Bachelard, describe los espacios poéticos como aquellos que:

(...) Aspiran a determinar el valor humano de los espacios de posesión, de los espacios defendidos contra fuerzas adversas, de los espacios amados. Por razones frecuentemente muy diversas y con las diferencias que comprenden los matices poéticos, son espacios ensalzados. A su valor de protección que puede ser positivo, se adhieren también valores imaginados, y dichos valores son muy pronto valores dominantes. El espacio captado por la imaginación no puede seguir siendo el espacio indiferente entregado a la medida y a la reflexión del geómetra. Es vivido. Y es vivido, no en su positividad, sino con todas las parcialidades de la imaginación (Bachelard, 2000, p.22).

Así, en esa sensibilidad poética, hay una búsqueda de valores humanos que nos sugieren trascender lo tangible, para ahondar en la habilidad interpretativa que antecede toda creación. Así partimos de que, gracias a nuestro Habitar, recibimos un estímulo que nos conduce al menos, a tres grados interpretativos (pre-figuración, configuración y trans-figuración), los cuales a continuación se detallan.

\section{(PRE)FIGURACIÓN: LA RELACIÓN SUJETO-ESPACIO EN LA COTIDIANIDAD DE CONVERSAR Y HABITAR}

Para comprender esta primera fase, partimos de que nuestra idea de lo que el espacio puede ser, nuestras interpretaciones sobre él y la manera en la que lo comenzamos a construir mentalmente, están sentadas sobre la base de experiencias espaciales cotidianas. Es en la familiaridad con el espacio construido y el relato del espacio, que comienzan a gestarse las ideas de lo que consideramos positivo y/o negativo en un lugar.

Entonces, partiendo de que el lugar es el resultado del espacio topográfico sumado al espacio temporal; sabemos que un lugar es aquello que puede ser ubicado por coordenadas o referencias topográficas y que es afectado por el paso del tiempo. Luego, si al lugar se suman las distintas actividades de los sujetos, tenemos un 
evento; y finalmente, si en dicho evento se conjuga más que una actividad; una vivencia, tenemos un evento significativo.

Luego, el evento significativo nos permite habitar el espacio-tiempo y genera una experiencia trascendental y por lo tanto, memorable para él o los sujetos, lo que suscita un despertar de la existencia. Este intercambio es el fenómeno al que los arquitectos aprendemos a sensibilizarnos, pues la esencia de dicha experiencia trascendental es origen de la percepción del Habitar y las conversaciones sobre los eventos a nuestro alrededor, así como el estímulo para la construcción de relatos y proyectos (subjetivos y/o colectivos). Al respecto Hall comenta:

(...) es necesario inculcar a los arquitectos, los urbanizadores y constructores que, (...) debemos ver en el hombre un interlocutor con su medio ambiente. Es grandemente necesario revisar y ampliar nuestro modo de ver la situación humana, ser más comprensivos y más realistas, no sólo para con los demás, sino también para con nosotros mismos. Es esencial que aprendamos a leer las comunicaciones silentes tan fácilmente como las escritas o habladas (Hall, 2003, p.12-13).

Esto quiere decir que escuchar las ideas de las personas o participar de conversaciones asociadas al espacio y el Habitar, es lo que nos pone en contacto con una comprensión que sobrepasa los tecnicismos, reglas y criterios exclusivamente arquitectónicos, y nos permite sensibilizarnos y acercarnos inclusive a la manifestaciones silentes de lo que significan los espacios para las personas, de manera que accedemos al comportamiento, lenguaje corporal y gestos que crean en nosotros la posibilidad de una 'pre-interpretación'. Si bien es cierto, la mayoría de las ideas se dan a conocer en primera instancia oralmente, en la vida cotidiana las ideas emanan en múltiples lenguajes y "Cuando uno piensa mucho por sí mismo, encuentra inscrita mucha sabiduría en el lenguaje cotidiano" (Lichtenberg citado en Heidegger, 2009, p.11).

En ese sentido, desde la Filosofía nos referimos al acto cotidiano de conversar, como un estímulo para construir las obras escritas, en el cual debe entenderse la conversación en el amplio sentido de: conversar con uno mismo, conversar con una realidad o conversar con otros sujetos. De ahí surge un inter-texto que nos dice que en el proceso interpretativo, conversar presupone construir y lo construido (es decir, la forma escrita) presupone nuevamente conversar. Y a su 
vez desde la Arquitectura, nos referimos al acto cotidiano de Habitar como el estímulo para construir obras proyectadas, en donde las ideas en torno al Habitar, presuponen construir y lo construido presupone nuevas ideas sobre el Habitar.

Cabe destacar que, ante este primer intento por interpretar, nos invade un 'fenómeno de centro', al que podríamos describir como aquel en el que el sujeto actúa como un interpretador pasivo que recibe y absorbe de su entorno fenómenos tangibles y abstractos, entre los cuales la percepción de experiencias colectivas e individuales lo impulsa a crear sus propias ideaciones sobre el Habitar y recapacitar sobre los asuntos cotidianamente conversados, de donde extrae sus inquietudes y finalmente se retroalimenta.

Dentro de este fenómeno de centro, el sujeto está expuesto a una gran cantidad de perspectivas y contenidos que pueden reformar sus convicciones, presentarle una apertura de horizontes o confirmarle lo que ya tenía previsto. En todo caso, la riqueza de esta 'preinterpretación' radica en que las ideas se manifiestan vivas y en movimiento, pues nada está dado por sentado o permanentemente establecido y el rol del sujeto es abierto y receptivo a leer la realidad de los demás desde su contexto y escuchar hablar al 'otro' para recopilar información y mayormente comprender lo cotidiano. De hecho,

(...) la intención de hablar sólo puede hallarse en una experiencia abierta; aparece, como la ebullición en un líquido, cuando, en el espesor del ser, se constituyen unas zonas de vacío que se desplazan al exterior. En cuanto el hombre se sirve del lenguaje para establecer una relación viva consigo mismo o con sus semejantes, el lenguaje no es ya un instrumento, no es ya un medio, es una manifestación, una revelación del ser íntimo y del vínculo psíquico que nos une al mundo y a nuestros semejantes (Merleau-Ponty, 1993, p.213).

No obstante, esta postura de receptor le impide crear una interpretación distinta de la pre-interpretación, ya que se satura con los pensamientos ajenos y requiere continuar impregnándose de ideas hasta llegar a un estado de intriga, antes de empecinarse con los procesos (con)figurativos y (trans)figurativos que le siguen a esta fase.

Además, reconociendo que el proceso hermenéutico es permanentemente inacabado y por lo tanto crea un punto de comienzo y recomienzo de los cambios sobre la vida cotidiana; 
debemos considerar que eventualmente cuando las ideas transmitidas por los otros se llegan a convertir en lenguaje arquitectónico o en lenguaje literario; la experiencia se hace transmisible como esencia poética a otros sujetos. Esto le confiere la posibilidad de convertirse en una experiencia compartida que pasa a formar parte de la memoria colectiva, en una suma de eventos que conforman la historia.

Por último, los productos de la interpretación hermenéutica avivan, agitan y asocian las ideas de formas nuevas, generándose un cambio sobre el Habitar y el conversar cotidianos en un proceso infinito, en el cual se transforman las ideas sobre el Habitar y en las conversaciones surgen nuevos debates y agendas de discusión; como estímulos inéditos que finalmente tienen su derivación sobre la práctica, al afectar críticamente los productos de la construcción en el Espacio y el Tiempo.

\section{(CON)FIGURACIÓN: LA RELACIÓN SUJETO-ESPACIO EN LA CONSTRUCCIÓN DE LA FORMA ESCRITA Y LA FORMA PROYECTUAL}

En esta segunda fase tenemos que, tal y como lo menciona Heidegger; Habitar presupone construir. En ese sentido, el paso a la (con)figuración es siempre relevante, pues es por medio de la acción de construir, que la Arquitectura se hace visible a la sociedad entera. Así como, "la música precisa de su ejecución. La Arquitectura necesita ser ejecutada" (Zumthor, 2004, p.56).

Tal proceso de construir comienza gracias a una serie de conversaciones e ideas que forman parte de la convivencia y el habitar cotidiano, que se suman y entrelazan generando asombro y curiosidad, pero en especial un despertar de conciencia sobre la necesidad de construir una propuesta concreta que responde o lanza preguntas sobre determinado(s) fenómeno(s). A este despertar es al que hemos llamado: "puesta-en-intriga" (Ricoeur, 2003, p.17), basándonos en la aproximaciones hermenéuticas de Ricoeur, pero proponiendo de forma inédita las asociaciones que hilan su significado para el proceso interpretativo arquitectónico que aquí se propone.

Esta intriga es la que nos estimula a familiarizarnos con ciertas temáticas, en busca de poder concretar lo mental-interpretativo, 
mediante la ejecución manual de una obra. Esto implica que esta fase nos refiere a un 'hacer' y es el punto en el que las ideas se materializan. Antes teníamos que la percepción de lo interpretado se daba de manera oral y ahora tenemos que aquello viaja de la mente a la mano y se torna visible.

Cabe aclarar que por ejemplo, el cambio del relato oral, al relato escrito, originó también el cambio del espacio sonoro (que requiere estar en él para ser escuchado) al espacio visual (que es descrito a través de la proyección de un relato). Y luego con ello el cambio del lenguaje escrito por el del impreso, lo que ya de por sí creo un cierto distanciamiento en cuanto a la relación del creador con sus interlocutores.

Este distanciamiento aumenta dramáticamente con el paso a la imagen, en el que se espera que la imagen aporte ante todo un significado, cuando en realidad en muchos casos la imagen no tiene un relato de fondo y por tanto, aunque aparente laboriosidad, está vaciada de significados. Finalmente, el ojo separa al sujeto del mundo, a diferencia de los demás sentidos que requieren de una cierta cercanía.

En su libro Oralidad y escritura, Walter J. Ong explica:

'Aunque las palabras están fundadas en el discurso oral, la escritura
las encierra tiránicamente para siempre en el campo visual (...). Una
persona que ha aprendido a leer no puede recuperar plenamente el
sentido de lo que la palabra significa para la gente que sólo se
comunica de manera oral' (Ong citado en Pallasmaa, 2006, p.24).

De hecho, las obras proyectadas que se comunican a través de planos impresos y las formas escritas se restringen al campo visual, excepto en un caso; cuando se trata de poesía. La poesía está hecha para ser dicha y darle un significado a las palabras aún más enriquecido gracias a su intensidad, tono y pronunciación. De ahí que, si la Arquitectura se expresara como poesía, entonces los espacios visuales se podrían convertir en espacios sonoros de intercambio con otros sujetos y a través de la manifestación de conversaciones e ideas, se reiniciaría la primera fase del proceso interpretativo que nos acaba conduciendo a una Hermenéutica de la Arquitectura.

"Según Cézanne, 'el propio paisaje piensa en mí y yo soy su consciencia'. Una obra de arte funciona como otra persona con quien 


\begin{abstract}
uno conversa inconscientemente. (...) proyectamos nuestras emociones y sensaciones sobre la obra. Tiene lugar un curioso intercambio: prestamos nuestras emociones a la obra, mientras que la obra nos presta su autoridad y su aura. Finalmente, nos encontramos a nosotros mismos en la obra. La idea de 'identificación proyectiva' de Melanie Klein propone que, de hecho, toda interacción humana implica la proyección de fragmentos del yo sobre otra persona (Pallasmaa, 2006, p.66-67).
\end{abstract}

Este intercambio -que no es exclusivo de la obra de arte- es lo que permite a las personas concientizar hechos y circunstancias de la vida cotidiana a través de una conversación inconsciente con las intervenciones proyectuales y las formas escritas.

Por otro lado, a pesar de que "el acto de escribir, está institucionalizado actualmente en el libro, el sistema de la edición y el personaje del escritor" (Foucault, 1992, p.31 [paráfrasis]), tanto se puede relatar mediante la forma escrita, como mediante la intervención proyectual (si ambas cuentan con sensibilidad poética), cada una narra un hecho espacio-temporal y es en la lectura de ese relato, mediante las historias y vivencias, que se suscita la conversión del pasado en presente y la posibilidad de atraer lo distante, ósea, hacer del futuro y todo lo que parece poco probable, algo de lo que se conversa en el 'Ahora'. En ese nudo del espacio-tiempo, de todo lo anterior y posterior que converge en los acontecimientos actuales, se nutre la interpretación que resultará en una construcción de los actos cotidianos concientizados. En ese aspecto, la Arquitectura llevada a la ejecución de una obra es una representación de la vida cotidiana tomando forma y una evidencia del Habitar arquitectónico y el conversar filosófico.

Ludwig Wittgenstein, cuya Filosofía tiende a separarse de la imaginería del cuerpo, reconoce la interacción entre la obra filosófica y arquitectónica con la imagen del yo [al decir]: 'En realidad, trabajar en Filosofía -como en muchos sentidos en Arquitectura- no es más que trabajar sobre uno mismo, sobre la propia interpretación de uno mismo, sobre cómo uno ve las cosas' (Pallasmaa, 2006, p.12).

Así, luego de familiarizarnos con las ideas que nos han intrigado, toda esa información es filtrada y por lo tanto personalizada por nuestra propia perspectiva de las cosas, en el sentido de que, lo que resulta relevante para un sujeto, puede ser ignorado o degradado por otro. De esa filtración, surge la creación de la trama del relato o del partido 
arquitectónico, que va acorde con la manera en la que se construyen los nexos del fenómeno o fenómenos a los que nos enfrentamos, y las ideas y variables que hemos decidido discriminar.

Al ejecutar esta discriminación, nos encontramos con que elementos que se encontraban disociados en el contexto y la vida cotidiana se unen para crear un complot o plan, lo que conduce a jerarquizar las variables e ideas, en lo que sería una interpretación neutralizada y eventualmente llegar a la conclusión del objeto narrativo u objeto arquitectónico, una vez que hemos definido nuestra intención y tomado decisiones que definen nuestro resultado 'final'.

Se habla de un resultado 'final' entrecomillado porque se considera que el sujeto que escribe o proyecta, si bien de alguna manera representa una figura de autoridad; esa autoridad no significa que la inserción de las ideas en el papel sean una verdad de conocimiento definitivo, ni mucho menos que por el hecho de estar impresas esas ideas, se pueda creer que en consecuencia están demostradas.

Lo único que es concluyente de un escrito o de una proyección es justamente que están ya construidos y llegan a un momento en el que se terminan -físicamente-, no obstante el final abierto y del que hace uso la interpretación es el de las ideas, conversaciones, formas escritas e intervenciones proyectuales como textos que se pueden confrontar hasta el punto de llegar a una nueva construcción.

Inclusive, el desencanto por el carácter axiomático del construir se destaca en una carta donde Platón rechaza la escritura, en este caso porque Dionisio se excedió creando un tratado de la Filosofía para demostrar su propio valor filosófico, pero que desde la perspectiva de Platón, era más bien una muestra de que no comprendía realmente la Filosofía y el larguísimo camino del conocimiento.

(...) el texto sobre el gran rechazo de la escritura está en la carta II, casi al final, donde Platón dice:

Reflexiona pues sobre esto y cuídate de tener que arrepentirte algún día de lo que hoy dejes divulgarse indignamente. La mayor protección [megistephylaké] será no escribir y aprender en cambio de memoria, porque es imposible que los escritos no terminen por ser de dominio público (Platón citado en Foucault, 2009, p. 254-255).

Platón defiende que el hecho de que la Filosofía no se pueda transmitir efectivamente como una fórmula que cualquier lector pueda tomar, memorizar e integrar a su conocimiento, es un motivo esencial para que la escritura de la Filosofía carezca de sentido. Para 
Platón, enmarcar la Filosofía en un tratado que supuestamente habla sobre los asuntos esenciales a la Filosofía, era reducirla demasiado; pero más que nada es interesante este ejemplo porque da cuenta del carácter concluyente de las formas escritas. Algo a lo que también ha hecho alusión Foucault al decir: "El texto escrito no está vivo; no puede defenderse por sí solo (...)" (Foucault, 2009, p.341).

Es debido a esto que nos referimos a una muerte de la idea en esta fase, pues se trata de una experiencia que se encierra en sí misma, ya que tanto lo escrito en el libro, como lo edificado en la tierra o lo pintado en un lienzo, se constituyen como un proceso que inicia y termina.

Barthes, quien realiza un desciframiento del signo expresivo impreso en obras de distinta índole, describe por ejemplo, en 'La Cámara Lúcida', la imagen de la fotografía como un texto que una vez hecho, llega a un estado de completitud y por lo tanto; muerte. Tal afirmación, dada por el congelamiento de un instante que se queda plasmado en una imagen, es análoga a los textos de la obra escrita y la obra arquitectónica, que también una vez que llegan a considerarse terminados, se quedan inmóviles y se convierten en momificaciones de la acción y el tiempo.

\footnotetext{
La fotografía, [así como el relato escrito y la obra proyectada], es más que una prueba: no demuestra tan solo algo que ha sido, sino que también y ante todo demuestra que ha sido. En ella permanece ante todo la intensidad del referente, de lo que fue y ya ha muerto. (...) El referente se encuentra ahí, pero en un tiempo que no le es propio. (...) un trámite tanatológico que nos presenta de pronto, abruptamente, lo que fue, tal como fue (Barthes, 1989, p.22-23).
}

En ese sentido, el arquitecto, el fotógrafo y el escritor (entre otros), son como taxidermistas; que utilizan distintas técnicas para retener un instante concreto y un fragmento espacial que 'encuentra la muerte' a través de su finalización y que simbólicamente, son testimonio de que una serie de hechos han sido realidad, dando como resultado la creación de algo.

Esto los conduce a desdoblarse de sí mismos, actuando como yo y el otro simultáneamente con la convicción de que de esta forma será posible procesar las ideas, conversaciones y necesidades de los otros a partir del discernimiento del yo, que constantemente se coloca en la trinchera del otro para dotar a la creación de una integridad que ve por el entendimiento de los demás y el auto-entendimiento al mismo 
tiempo. "No se trata en efecto de contemplar, sino de vivir la existencia en toda su calidad inmediata. La contemplación se desdoblaría en ser contemplante y ser contemplado" (Bachelard, 2000, p.202).

Es justamente mientras escribimos o proyectamos nuestra obra que simultáneamente comenzamos a cambiar nuestra manera de pensar y a dejar de ser los que éramos. Foucault agrega: "Más de uno, como yo sin duda, escriben para perder el rostro. No me pregunten quién soy, ni me pidan que permanezca invariable (...)" (Foucault, 1979, p.29). Y efectivamente, al escribir, encontramos nuestra facultad para ser 'el otro' y esto inevitablemente nos transforma, pero simultáneamente nos remite a una verdad interior sobre quién es 'el yo'. "En 1978, Foucault afirma en una entrevista que le hace Trombadori, periodista italiano: 'Soy un experimentador, en el sentido de que escribo para modificarme a mí mismo y no pensar más de la misma manera que anteriormente'" (García, 2002, p.30).

Al respecto, Barthes analiza concienzudamente la sensación de ser varias personas en un mismo momento, al describir el fenómeno de ser retratado fotográficamente. Dice:

\footnotetext{
Ante el objetivo soy a la vez: aquel que creo ser, aquel que quisiera que crean, aquel que el fotógrafo cree que soy y aquel de quien se sirve para exhibir su arte. Dicho de otro modo, una acción curiosa: no ceso de imitarme, y es por ello por lo que cada vez que me hago (que me dejo) fotografiar, me roza indefectiblemente una sensación de inautenticidad, una impostura (...) no soy ni sujeto ni objeto (...) me convierto verdaderamente en espectro (Barthes, 1989, p.41-42).
}

Ahora bien, si en vez de retratar una persona, se habla de escribir un relato o proyectar una obra; sucede lo mismo; el relato y la obra son al mismo tiempo lo que son, lo que se desearía que los demás piensen que son, lo que el escritor o el arquitecto quieren que sean y finalmente los medios a través de los cuales se exhibe un resultado. Son tantas cosas simultáneamente, que una vez que se finalizan, tal y como una persona que es retratada; se desapropian de sí mismos al convertirse en objetos en las manos de otros.

Esa desapropiación es necesaria, porque si bien durante su construcción el creador se apodera de su relato y de su Arquitectura; una vez que el proceso termina, "aunque la Arquitectura quiera lo que quiera y busque significar lo que quiera decir, será desviada" (Baudrillard \& Nouvel, 2001, p.21). Esto quiere decir que la obra, con 
toda su intención y simbolismo; bien puede ser recibida con preceptos muy similares a los de la persona que la creó, pero también a lo largo del tiempo, su valor se diversifica, así como las experiencias, opiniones e ideas en torno a esa misma obra; ocasionando un despliegue de significados que invitan a pensar que el objeto logrado está ahí para ser interpretado.

Un objeto logrado, en el sentido de que existe más allá de su propia realidad, es un objeto que crea una relación dual, una relación que puede pasar por el desvío, por la contradicción, por la desestabilización, pero que, efectivamente, pone frente a frente la pretendida realidad de un mundo y su ilusión radical (Baudrillard \& Nouvel, 2001, p.19).

Resulta sugestivo como, encontrarse con un relato bellamente expresado o con una obra arquitectónica lograda, es en términos estrictos como los que usa Barthes para referirse a la fotografía; lo mismo que encontrarse con una cuestión inanimada, pero que sin embargo, nos anima. Barthes describe las emociones provocadas por una fotografía bajo los siguientes términos:

[La primera] cuya emoción es impulsada racionalmente por una cultura moral y política (...) de un afecto mediano, casi de un adiestramiento de interés humano (...): es el studium. [Y la segunda es el] (...) punctum que es también: pinchazo, agujerito, pequeña mancha, pequeño corte y también casualidad. El punctum de una foto es ese azar que en ella me despunta (pero que también me lastima, me punza) (Barthes, 1989, p.57-59).

En referencia a la Arquitectura y a la Escritura, ambos fenómenos tienen cabida, pues pueden provocar un significado humano universal (studium) así como una emoción que surge subjetivamente (punctum). Y efectivamente, una obra es capaz de conmovernos de distintas maneras; pero la explicación o la puesta en conciencia de lo que anima esas obras, es labor de la Hermenéutica.

Ahora bien, en esta segunda fase del proceso interpretativo el sujeto atraviesa nuevamente otro 'fenómeno de centro', en el cual actúa como un actor creativo y se encuentra inmerso en la generación de preguntas y respuestas para llegar a un producto concluyente que corresponde al universo de un conjunto de partes, a su vez inmersas en la totalidad de la gran red del conocimiento. 
Sin embargo, se dice que la interpretación resulta neutralizada, por el hecho de que aunque el sujeto puede desdoblarse para capturar las necesidades y posibles percepciones que los demás tengan de su obra, así como para conversar consigo mismo sobre lo que hace; no puede desdoblar el espacio-tiempo para ver la parte y el todo de la obra simultáneamente, ni puede obviar que se encuentra a la mitad de un proceso interpretativo mayor.

Además de que, puesto que la interpretación es un acto que sucede respecto al 'otro'; mientras una obra se está escribiendo o proyectando, sigue formando parte del 'yo', lo que no le impide al sujeto ser auto-crítico, pero sí le impide auto-interpretarse. O en palabras de Bachelard: "La brizna de musgo puede bien ser pino, pero el pino no podrá nunca ser brizna de musgo. La imaginación no trabaja en ambos sentidos con la misma convicción". (Bachelard, 2000, p.147). Y así, quien construye, no puede imaginar su obra mientras la está construyendo, desdoblándola al reverso y anverso.

En efecto, en el ejercicio regular de la escritura, no hay una autoescritura -exceptuando el diario personal del escritor-, así como en el ejercicio de la Arquitectura, "no hay auto-Arquitectura" (Baudrillard \& Nouvel, 2001, p.38), -exceptuando la casa particular que un arquitecto pudiera hacer para sí mismo-. En ese sentido, la acción de desdoblamiento que ejecuta el sujeto (actor creativo) en la construcción de una obra, es necesaria, no solo como medio para que el creador se entienda a sí mismo, sino porque su producción será percibida también por otros sujetos.

Por otro lado, también es a través del sujeto en su rol de actor creativo que las ideas alcanzan su universalidad, pues si no hubiese filósofos, artistas y arquitectos (entre otros) que construyeran algo con el conocimiento hasta ahora acumulado, muy difícilmente tales conocimientos podrían trascender tantas fronteras, multiplicarse y reconocerse en distintos lugares sobre la faz de la Tierra. Ante esto Foucault menciona:

"¿En qué momento nos constituimos como sujetos universales? Pues bien, cuando, como sujetos racionales, nos dirigimos al conjunto de los seres racionales. Y entonces, en esa actividad que es precisamente y por excelencia la del escritor que se dirige al lector, en ese momento, encontramos una dimensión de lo público que es al mismo tiempo la dimensión de lo universal" (Foucault, 2009, p.5253). 
Es decir que al manifestar las ideas sobre el papel, finalmente se efectúa un intercambio con el 'otro', dándole la oportunidad de interpretar o al menos considerar lo que como actores, hemos creado. De forma que,

\footnotetext{
No se trata de señalar la verdad de quienes somos, no se trata de diagnosticar eso que somos para dar cuenta de ello. El objetivo no es "demostrar" quienes somos, sino todo lo contrario, mostrar cómo podemos "ser de otro modo". Así pues, si la escritura debe apuntar a hacer una experiencia de transformación, si de lo que se trata es de hacer partícipes a otros de las líneas de fragilidad de nuestro presente en vistas a una transformación, esa escritura no puede apoyarse sobre una mera verdad-conocimiento. Por lo tanto, no puede ejecutarse como una verdad-demostración, en tanto que expresión y efecto de la palabra del profesor, de la disciplina, de la universidad, del experto (Jordana Lluch, 2013, p.209).
}

Esto, reivindica la necesidad de una fase (con)figurativa, no con la única intención 'del construir por el construir' o con la finalidad de institucionalizar o fundar una verdad, sino para generar insumos en la construcción del conocimiento y la concepción de nuevos productos hermenéuticos inspirados en dichas obras.

\section{(TRANS)FIGURACIÓN: LA RELACIÓN SUJETO-ESPACIO EN LA LECTURA DEL RELATO Y LA CIUDAD}

(...) Según los tiempos y los lugares, según los objetos leídos y las razones de la lectura, los gestos cambian. Se inventan nuevas actitudes y otras desaparecen. Del rollo antiguo al códex medieval, del libro impreso al texto electrónico, diversas rupturas marcan hitos en la larga historia de las maneras de leer (Chartier citado en Cordón et al, 2013, p.13).

Sin embargo, la lectura que se propone desde la Hermenéutica, bien puede ser de: un códex, un papiro, un plano, una comunidad, un edificio, un libro digital y muchos otros que pueden servir a una misma lectura, ya que la interpretación no se prescribe al soporte sobre el cual se encuentra el texto.

Así finalmente, tenemos la tercera fase, en la cual este proceso se nos acaba de confirmar como una lectura de la vida cotidiana y de las obras escritas, proyectadas y edificadas de la Arquitectura, como textos que revelan el asunto hermenéutico permanentemente 
inacabado, abierto y provocador de nuevas asociaciones en la red del pensamiento. Ante esto, cabe preguntarse:

"¿Habla la memoria de las piedras igual de claro que la de los textos?" (Ricoeur, 2003, p.9). A groso modo se podría decir que ambos hacen relatos de nuestro pasado, presente y futuro; pero es en el aprendizaje de su interpretación, que encontramos la riqueza reveladora del espacio hecho texto y el texto hecho espacio.

Como nos advierten los filósofos, las palabras están preñadas de significados existenciales. En ellas, los seres humanos han acumulado innumerables experiencias, positivas y negativas, experiencias de búsqueda, de encuentro, de certeza, de perplejidad y de inmersión en el Ser. Tenemos que extraer de las palabras su riqueza escondida (Boff, 2002, p.72).

La resolución de una Hermenéutica de la Arquitectura, es justamente el medio que nos facultará, para entender cómo establecer nuestras interrelaciones con el espacio-texto, lo que esencialmente vendría a difuminar los límites entre la teoría y la práctica, así como a promover la integración de nuestros procesos interpretativos, con las proposiciones de un nuevo paradigma.

Paul Ricoeur, ha tratado la hermenéutica en términos del espacio arquitectónico, lo que resulta de gran utilidad para comprender el potencial del texto sobre la relación sujeto-espacio. Fundamentalmente, al basarnos en las ideas hermenéuticas propuestas por Ricoeur, partimos de la idea de que tanto el espacio que es resuelto por medio de la Arquitectura, como el tiempo, que es resulto por medio del relato, son textos y esto le confiere a ambos la posibilidad de ser interpretados.

\footnotetext{
La lectura siempre es apropiación, invención, producción de significaciones. Según la bella imagen de Michael Certeau, el lector es un cazador furtivo que recorre las tierras de otro. Apropiado por la lectura, el texto no tiene exactamente -o en absoluto- el sentido que le atribuyen su autor, su editor o sus comentaristas (Chartier citado en Cordón et al, 2013, p.13).
}

En efecto, la narración o relato y la proyección de obras arquitectónicas, están íntimamente relacionadas con la memoria, en tanto que lo que se narra se puede narrar porque es una manifestación de ideas sobre lo que pasó o lo que se inventa, pero que finalmente se construyen con base en lo que se ha interpretado 
hasta el presente, ósea, con lo ya sucedido. Ricoeur explica que se trata de "hacer presente la 'ausencia-que-ha-sido' [y agrega] (...) a mí me parece que la gloria de la Arquitectura consiste en hacer presente no lo que ya no existe más, sino lo que ha existido a través de lo que ya no existe" (Ricoeur, 2003, p.9-10), lo que a partir de este punto establece un nexo entre el relato del tiempo y la Arquitectura del espacio, además como medios recíprocamente interpretables e interpretativos; y por otro lado, como realidades y representaciones de la realidad que nutren la lectura hermenéutica.

Ahora bien, sabemos que las realidades estarán presentes y listas para su lectura, pero es gracias a la construcción de representaciones como las propuestas arquitectónicas y literarias, que decimos que la percepción de lo interpretado ahora es háptica, porque conjuga todo aquello que ya ha sido construido en la fase anterior, de manera que ahora podríamos acercarnos con todos nuestros sentidos y obtener una lectura de ello; lo que además nos permite decir que los productos interpretativos ya no solo se basan en algo mental (primer fase) y manual (segunda fase); sino también visual.

Mediante la lectura del Tiempo y el Espacio (y sus respectivas construcciones) se generan dos productos importantes en los aspectos que tienden a lo: subjetivo y objetivo. Desde el punto de vista subjetivo, nos encontramos con la lectura de las realidades que se manifiestan en la vida cotidiana, en las ideas y conversaciones que están ahí para ser cuestionadas y eventualmente activadas. Esto significa estar atentos a escuchar y considerar las ideas del 'ciudadano común', así como las del 'experto' o las de un colectivo; pues cada uno de ellos aporta desde su propia comprensión de la realidad, un significado que podría hacer emerger asociaciones de ideas hasta entonces desconocidas o inadvertidas.

Merleau-Ponty en el libro, La Prosa del Mundo dice: El escritor es él mismo como un nuevo idioma que se construye, se inventa medios de expresión y se diversifica según su propio sentido.

Pero la escritura en tanto 'idioma' es también el producto de voces, de silencios y de gestos que no cobran apariencia de obra. Las palabras, sus conceptos y sus imágenes, dan a esta praxis relevos de significación y de comunicación. Al fin, cada uno es un 'nuevo idioma' naciente, y el mundo es el espacio común de significancias idiomáticas (Nancy, 2003, p.134). 
En esa medida, cada persona involucrada en el asunto que se trata de interpretar, representa en sí misma un 'idioma' y una perspectiva particular para abordar el Habitar y entre más lecturas de la cotidianidad sumamos, más se enriquece el gran y complejo lenguaje de la convivencia entre los seres humanos y el espacio construido. Luego, desde el punto de vista objetivo, nos encontramos con la lectura de las representaciones; que por su carácter formal y concluyente, dificultan la posibilidad de una lectura subjetiva, debido a que, a diferencia de las ideas que son intangibles; en este caso, las obras arquitectónicas y literarias son evidencias de lo existente y pueden ser reconocidas por muchas otras personas que ya las han estudiado y creado juicios de valor, escritos y argumentos válidos en torno a ellas. Al respecto Holl comenta:

\footnotetext{
Al escribir sobre Arquitectura y percepción, uno se ve inevitablemente acechado por la pregunta: ¿somos capaces de entrever la palabra en la forma construida? Si se pretende que la Arquitectura trascienda su condición física, su función como mero refugio, entonces su significado como espacio interior debe ocupar un espacio equivalente dentro del lenguaje. El lenguaje escrito debería, pues, asumir las silenciosas intensidades de la Arquitectura (Holl, 2011, p.7).
}

De esta forma, nos encontramos ante la lectura de objetos concretos como libros y proyectos arquitectónicos; por un lado los espacios que constantemente se construyen con madera, vidrio, metal y concreto, entre otros y por otro, los que se construyen con letras y signos de puntuación; que lastimosamente son menos populares como medios para expresar el espacio, a pesar de ofrecer tan poderosas visualizaciones. Sobre este último aspecto, Pallasmaa menciona:

\footnotetext{
La memoria nos devuelve a ciudades remotas y las novelas nos transportan a través de ciudades invocadas por la magia de la palabra del escritor. Las habitaciones, las plazas y las calles de un gran escritor son tan reales como cualquiera que hayamos visitado; las ciudades invisibles de Italo Calvino han enriquecido para siempre la geografía urbana del mundo (Pallasmaa, 2006, p.68).
}

Además, tenemos que para esta fase surge un inter-texto a considerar, que nos dice que: cuando se construye una forma escrita o una intervención proyectual, esto es un reflejo del conversar y el Habitar y luego en la lectura y relectura del Espacio y Tiempo construidos, hay una memoria de ese construir. 
Así, desde el punto de vista subjetivo llegamos a un primer producto; que sería la activación de la ideas. En donde gracias a la memoria del construir, surgen interrogantes sobre las intenciones, acciones, ideologías y conocimientos que motivaron a resolver una obra de determinada manera, de forma que en esta remembranza; Espacio y Tiempo son causa de la reconstrucción y eventual activación de las ideas y conversaciones que nos condujeron a las propuestas existentes y que ahora cobran un nuevo sentido, uso y asociación. Y desde lo objetivo, tenemos un segundo producto; que sería la reflexión, pues si las propuestas escritas y proyectadas son un reflejo de nuestro conversar y Habitar, al ser leídas son causa de reflexión sobre los estímulos que causan este reflejo y las propuestas en sí mismas.

Recordemos que "El escritor [y el arquitecto] es consciente de que el camino por él trazado será completado por las huellas de quienes lo paseen" (Cordón et al, 2013, p.15). de manera que estas reflexiones complementan y rematan el significado de lo que acontece y lo que se crea.

A raíz de estos dos productos, el sujeto pasa a ser un hermeneuta; pues experimenta un fenómeno de borde en el cual no se comporta exclusivamente como un interpretador pasivo ni como un actor creativo, sino que ejerce ambos papeles simultáneamente desde el margen. La transformación teórico-práctica por medio de su lectura, depende de su habilidad para enlazar estructuras de conocimiento existentes, sin caer en el abismo de los modelos totalizantes ni descomponer arbitrariamente los conceptos fundantes de sentido. En el margen, el 'yo' y el 'otro' evolucionan y así la relación sujeto-espacio entra en un estado dialógico; además de que las nuevas asociaciones entre hechos e ideas contribuyen a la conectividad de los conocimientos y el descubrimiento de teorías y prácticas dispuestas a crecer y cambiar.

Es en este punto que el sujeto logra ir más allá de su propia transformación para superar las fases anteriores y transformar el Tiempo y el Espacio a través de los productos hermenéuticos. Aquí, las ideas y las construcciones, sin importar si desde hace mucho se habían adormecido o si habían sido despreciadas; regresan a la vida y cobran sentido al ser reflexionadas y activadas en la generación de una nueva realidad que recrea e intensifica lo que ya se establecido como ordinario. 
En todo texto literario [y obra de Arquitectura] el lector funciona como exégeta, como actor indispensable de la comunicación -puesto que la obra es obra, o el poema es poema, en tanto en cuanto alguien recibe el mensaje y lo descifra-, y como otorgador último de significado. De esta manera, podemos considerar que la lectura crea lo leído y la interpretación crea lo interpretado, al igual que la luna, en su simbolismo, es la luna porque los humanos desde la Tierra la observamos y la interpretamos así (Cordón et al, 2013, p.14).

La interpretación hermenéutica da como resultado una reflexión, que así como la reflexión de la luz demuestra un cambio de dirección, en este caso, puede cambiar la dirección en la manera de construir las formas escritas y las intervenciones proyectuales, creándose nuevas propuestas de obras arquitectónicas y escritas. O también, puede dar como resultado una activación, que así como la activación de una lámpara queda demostrada al arrojar luz o quemante calor sobre las cosas; la interpretación activa las ideas y conversaciones al iluminarlas o estremecerlas; creándose nuevas agendas de discusión y debates. Por supuesto, en el mejor de los casos se llega a los dos resultados; sin embargo, ambos procesos quedan siempre inconclusos y en constante transformación, ya que al formar parte de un pensamiento en red, se admite su inmersión nuevamente en lo cotidiano, lo que a su vez implica continuar revolucionando el proceso de (pre-con-trans) figuración y de pensamiento asociativo; que a su vez crean y re-crean el nuevo conocimiento.

\section{BIBLIOGRAFIA}

Arenas Luis \& Fogué Uriel. (2011) Planos de [Inter]sección. Materiales para un diálogo entre filosofía y arquitectura. Madrid: Lampreave. Recuperado de: http://www.interseccion.info/index.php?/publicaciones/libros/

Bachelard, Gaston. (1997). El agua y los sueños, México: Ed. Fondo de Cultura Económica.

Bachelard, Gaston. (2000). La Poética del Espacio. Buenos Aires: Ed. Fondo de Cultura Económica. 
Barthes, Roland. (1989). La Cámara Lúcida. Barcelona: Ediciones Paidós.

Baudrillard, Jean. \& Nouvel, Jean. (2001). Los objetos singulares: arquitectura y filosofía. Buenos Aires: Ed. Fondo de Cultura Económica.

Boff, Leonardo. (2002). El Cuidado Esencial: Ética de lo Humano Compasión por la Tierra. Madrid: Editorial Trotta.

Cordón, José; Gómez, Raquel; Arévalo, Julio. (2013) Documentos Electrónicos y Textualidades Digitales. España: Ediciones Universidad de Salamanca. Versión en línea.

Recuperado de:

https://books.google.co.cr/books?id=XI7UAgAAQBAJ\&printsec=fron tcover\#v=onepage \&q\&f=false

Foucault, Michel. (1979). La Arqueología del Saber. México: Siglo Veintiuno Editores.

Foucault, Michel. (1992), El Orden del Discurso (González, A, trad.) Buenos Aires: Tusquets Editores

Foucault, Michel. (2009). El Gobierno de Sí y de los Otros. Curso en el Collége de France (1982-1983) Argentina: Fondo de Cultura Económica

García, María Inés. (2002). Foucault y El Poder. México: Universidad Autónoma Metropolitana, Unidad Xochimilco, Depto. de Política y Cultura

Hall, Edward. (2003). La Dimensión Oculta. (Blanco, F, trad.) México: Siglo Veintiuno Editores.

Heidegger, Martin. (2009). El Arte y el Espacio. (Escudero, J, trad.) Barcelona: Herder Editorial, S.L. (Obra original publicada en 1969)

Holl, Steven. (2011). Cuestiones de Percepción: Fenomenología de la Arquitectura. Barcelona: Editorial Gustavo Gili 
Jordana Lluch, Ester. (2013). Foucault: La Escritura como Experiencia de Transformación. Revista de Filosofía en Línea, Lo Sguardo, №11, pp. 199-211. Recuperado de: http://www.losguardo.net/public/archivio/num11/articoli/2013_11_Es ter_Jordana_Foucault_Escritura_experiencia_transformacion.pdf

Larroque, Jimena. (24 de setiembre, 2015). Julia Kristeva: "El humanismo no es un sistema, es una refundación permanente" Revista de Cultura Independiente y Plural (distribuida por el periódico español: El Mundo). Versión en línea. Madrid: El Cultural Electrónico, S.L. Recuperado de: http://www.elcultural.com/noticias/letras/JuliaKristeva-El-humanismo-no-es-un-sistema-es-una-refundacionpermanente/8366

Merleau-Ponty, Maurice. (1993). Fenomenología de la Percepción. Barcelona: Planeta-De Agostini. Obra original publicada en 1945.

Nancy, Jean-Luc. (2003) El Sentido del Mundo. (Casas, J, trad.) Buenos Aires: La Marca Editora.

Pallasmaa, Juhani. (2006). Los Ojos de la Piel: La Arquitectura y Los Sentidos. Barcelona: Editorial Gustavo Gili

Ricoeur, Paul. (2003). Arquitectura y Narratividad. Revista internacional Arquitectonics: Mente, Territorio y Sociedad, $\mathrm{N}^{\circ} 4$. Ediciones UPC. Universidad Politécnica de Cataluña, pp. 9-30

Zumthor, Peter. (2004). Pensar La Arquitectura. Barcelona: Editorial Gustavo Gili. 